\title{
Las galerías drenantes en España: cuantificación y clasificación tipológica de los sistemas horizontales de captación de aguas subsuperficiales
}

\author{
Antequera Fernández, Miguel; Iranzo García, Emilio; Hermosilla Pla, Jorge. \\ Departamento de Geografía, Universidad de Valencia. \\ Miguel.Antequera@uv.es; emilio.iranzo-garcia@uv.es; jorge.hermosilla@uv.es
}

\begin{abstract}
Resumen. Desde el año 2003 la unidad de investigación ESTEPA (Estudios del Territorio, del Paisaje y del Patrimonio) viene trabajando en una infraestructura de datos espacial (IDE) para el patrimonio hidráulico, en la que hasta el momento se han cuantificado y clasificado más de 8.000 galerías drenantes. El objetivo de la presente comunicación es presentar algunos de los resultados del catálogo y del ensayo de tipificación de estos elementos hidráulicos de captación en España.
\end{abstract}

Palabras clave: qanat, foggara, galería drenante, clasificación tipológica, patrimonio hidráulico.

\begin{abstract}
Since 2003 the ESTEPA (Landscape, Territory and Heritage Studies) research group has been developing an Spatial Data Infrastructure (SDI) for water heritage, quantifying and classifying more than 8,000 drainage galleries. The aim of his paper is to present some of the results of this vast catalogue and to essay a typology of these hydraulic collection elements in Spain.
\end{abstract}

Keywords: qanat, foggara, drainage galleries, typology, water heritage.

\section{Introducción}

Las galerías drenantes constituyen una modalidad de captación de agua subsuperficial propia de lugares donde las aguas superficiales no siempre garantizan el abastecimiento. El agua dulce es fundamental para la vida, pero al mismo tiempo es un recurso escaso e incierto y más aún en los países mediterráneos, donde unas condiciones climáticas e hidrológicas adversas han tenido que resolverse a través de respuestas tecnológicas de diversa índole. En España el acopio de agua ha condicionado históricamente la consolidación de los núcleos de población y el desarrollo de una agricultura de regadío. El clima y el roquedo son los dos factores esenciales que explican la disponibilidad de agua dulce. En el caso de España, los principales reservorios hídricos (caudales, manantiales o el propio freático) quedan totalmente condicionados una pluviometría y en menor medida por una litología, que favorecen o perjudican la captación de agua. Por su orografía y situación geográfica, España presenta una contrastada variedad climática tanto en lo que respecta a las temperaturas como a las precipitaciones, debido a la dinámica atmosférica, la situación latitudinal y la complejidad del relieve. Las precipitaciones son modestas (400-600 $\mathrm{mm}$ ) y estacionalmente irregulares en la mayor parte del territorio nacional, considerándose escasas $(300 \mathrm{~mm})$ en el sudeste peninsular. Las características del clima mediterráneo que dominan la mayor parte del territorio peninsular, contrastan con las de la franja septentrional del país. La España lluviosa se extiende por una estrecha faja en el norte y noroeste de la península, llegándose a superar los $2000 \mathrm{~mm}$ en los sectores mejor expuestos a los flujos húmedos cantábricos (Castro et al., 2005) y por la España subtropical de las islas Canarias más occidentales. 
Así pues, en la mayor parte de España las sequías son acusadas y las escorrentías permanentes parcas, lo que ha suscitado desde antiguo el ingenio de los habitantes para la captación y el manejo del preciado recurso desde las capas freáticas y acuíferos más superficiales. Las técnicas utilizadas han sido la captación mediante pozos verticales, técnica que necesita de una fuente de energía para elevar el agua hasta la superficie; y la captación mediante galerías casi horizontales, en las que el agua fluye por una conducción subterránea hasta que sale a la superficie, gracias a la acción de la gravedad. Esta técnica e infraestructura, originaria del Cáucaso e Irán (Barceló, 1986) recibe diferentes denominaciones según la región (minas de agua, viajes de agua, galerías filtrantes, qanat, foggara, m'koula, karez...), habiéndose popularizado para el caso de España con el nombre de galería drenante (García et al., 2008). Una galería drenante es un túnel excavado por debajo de la superficie terrestre con el objetivo de alcanzar el agua del freático, para que fluya por acción de la gravedad hasta el exterior. El agua captada es fundamentalmente agua de de lluvia que tras infiltrarse queda retenida en capas permeables que descansan sobre capas impermeables (López-Camacho, 2001). Mediante la galería excavada esas aguas freáticas son concentradas y conducidas hasta la superficie durante un trayecto que puede oscilar desde los pocos metros hasta varios kilómetros.

Este tipo de técnica de captación presenta una serie de ventajas con respecto a otras, especialmente en ambientes donde la evapotranspiración es muy elevada como consecuencia de la insolación y las altas temperaturas. En primer lugar se minimizan las pérdidas de agua por evaporación o roturas del sistema de conducción. En segundo lugar, no se necesita un gasto energético extraordinario para su extracción, ya que el agua fluye hacia el exterior por una conducción de mínima pendiente, gracias a la fuerza de la gravedad. $\mathrm{Y}$ en tercer lugar las aguas quedan salvaguardadas de agentes contaminantes exteriores, si bien es cierto que con la proliferación de los fertilizantes agrícolas, las aguas subterráneas también pueden quedar afectadas. Esta técnica ancestral de captación y transporte de agua para el aprovechamiento agrícola y abastecimiento humano ha despertado el interés de la comunidad científica interesada en los sistemas de regadío y la creación de espacios irrigados, en el paisaje y el patrimonio del agua e incluso en la ingeniería hidráulica. Se ha efectuado una importante labor de identificación de galerías (Kobori, 1979; Goblot, 1979; Lambton, 1989; Lightfoot, 2000; Hermosilla, 2006; El Faiz y Ruf, 2010) pero existen discrepancias entre lo que es y lo que no es una galería drenante. Algunos investigadores se concentran en el análisis de la galería drenante tipo qanat, considerada como la máxima expresión de la técnica (Kobori, 2006); mientras que otros investigan cualquier tipo de galería horizontal y tratan de establecer tipologías de galerías en función del ambiente geomorfológico por el que discurre la galería, la técnica constructiva empleada o el tipo de agua captada (El Faiz y Ruf, 2010).

En esta comunicación se presenta una parte de nuestra investigación sobre galerías drenantes, en el marco de un macroproyecto que desde el año 2003 viene efectuando la unidad de investigación ESTEPA (Estudios del Territorio, Paisaje y Patrimonio) del Departament de Geografia de la Universitat de València, de identificación y catalogación del patrimonio del agua español, y más concretamente del proyecto auspiciado por el Ministerio de Medio Ambiente "Las galerías drenantes en España. Análisis y selección de qanat(s)" (2007-2008), con el código 2007/0808. No obstante sigue siendo una investigación abierta y en curso. Efectivamente, en otros proyectos se ha continuado la labor iniciada profundizando en la temática y analizamos a una diferente escala espacial este tipo de captaciones de aguas subterráneas. Ejemplo de esto último son los proyecto $\mathrm{I}+\mathrm{D}$, financiado por la Secretaría General de Política Científica y Tecnológica del Ministerio de Educación y Ciencia titulado "Galerías drenantes: estudio, evaluación y revalorización de un elemento 
singular del patrimonio del agua en la cuenca bidrográfica del río Júcar" (Hermosilla, 2012) (HUM2007-62342); las dos Acciones Especiales de la Universidad de Valencia, una para el sector del Vinalopó Alto y Medio en Alicante, el Norte de la provincia de Murcia y la parte de la provincia de Albacete integrada en la Confederación Hidrográfica del Segura (20062007), y otra para las galerías integradas en el sector del Alto Turia, en las provincias de Teruel, Cuenca y Valencia (2007-2008); y los efectuados en Túnez, en colaboración con investigadores tunecinos, mediante una Acción Integrada financiada por la Agencia Española de Cooperación Internacional para el Desarrollo (AECID), para el periodo 20102013 (Hermosilla y Moussa, 2011, 2012, 2013).

El objetivo general de este estudio es el de mejorar la comprensión de las características y el funcionamiento de las galerías drenantes en España, con el fin de ponerlas en valor como patrimonio, al ser creadoras de paisajes culturales y como una técnica y un modo eficiente de captación de agua, lo que garantiza una correcta gestión de los recursos hídricos y el mantenimiento de los ecosistemas agrícolas. Se pretende realizar una contribución para la comunidad científica del conocimiento de una técnica de captación de agua compleja, antigua y bastante desconocida, para poder efectuar su conservación y salvaguarda como un bien patrimonial. El diseño de una Infraestructura de Datos Espacial para el patrimonio hidráulico nos ha permitido catalogar, tipificar y establecer análisis de más de 8.000 galerías drenantes. Se pretende constatar cual es la relevancia real de las galerías drenantes en España y las diferentes variantes o tipologías presentes. Esta investigación queda justificada debido al volumen de captaciones horizontales localizadas en el conjunto de España y debido a sus diferencias tipológicas. Si bien es cierto que existe una clara concentración en las regiones peninsulares mediterráneas, también se han identificado galerías en espacios de clima oceánico, como en Galicia. Los resultados de la investigación han quedado plasmados en la publicación Las galerias drenantes en España. Análisis y selección de qanat(s) (Hermosilla, 2008), así como en diversas ponencias en Congresos y artículos en revistas. Asimismo se han organizado y participado en Seminarios Internacionales sobre galerías.

\section{Metodología}

La zona de estudio comprende la totalidad del Estado español, incluyendo los archipiélagos balear y canario, en los que además existe una presencia destacada de galerías. La metodología utilizada en este estudio queda sintetizada en la figura 1. Esta se fundamenta en los métodos de trabajo consolidados por la Unidad de Investigación ESTEPA en proyectos como "FOGGARA", financiado por la Comisión Europea (anualidades 20032006), en el que se analizaron las galerías de las provincias de Castellón, Valencia, Alicante, Murcia y Almería (Hermosilla, 2006). Esa investigación previa nos permitió poder utilizar una metodología contrastada para nuestro propósito. Una de las primeras tareas ha consistido en la consulta y análisis de las fuentes de información, tanto de las fuentes propiamente dichas (bibliografía, documentos en la red, consulta a expertos y usuarios, fuentes cartográficas) como de los archivos, ya sean históricos como contemporáneos. Se han revisado los archivos de los Ministerios de Fomento y Agricultura, los de algunos archivos Históricos Provinciales, de Diputaciones y Municipales, además de los de las Confederaciones Hidrográficas y los de las Comunidades de Regantes abastecidas por galerías. 


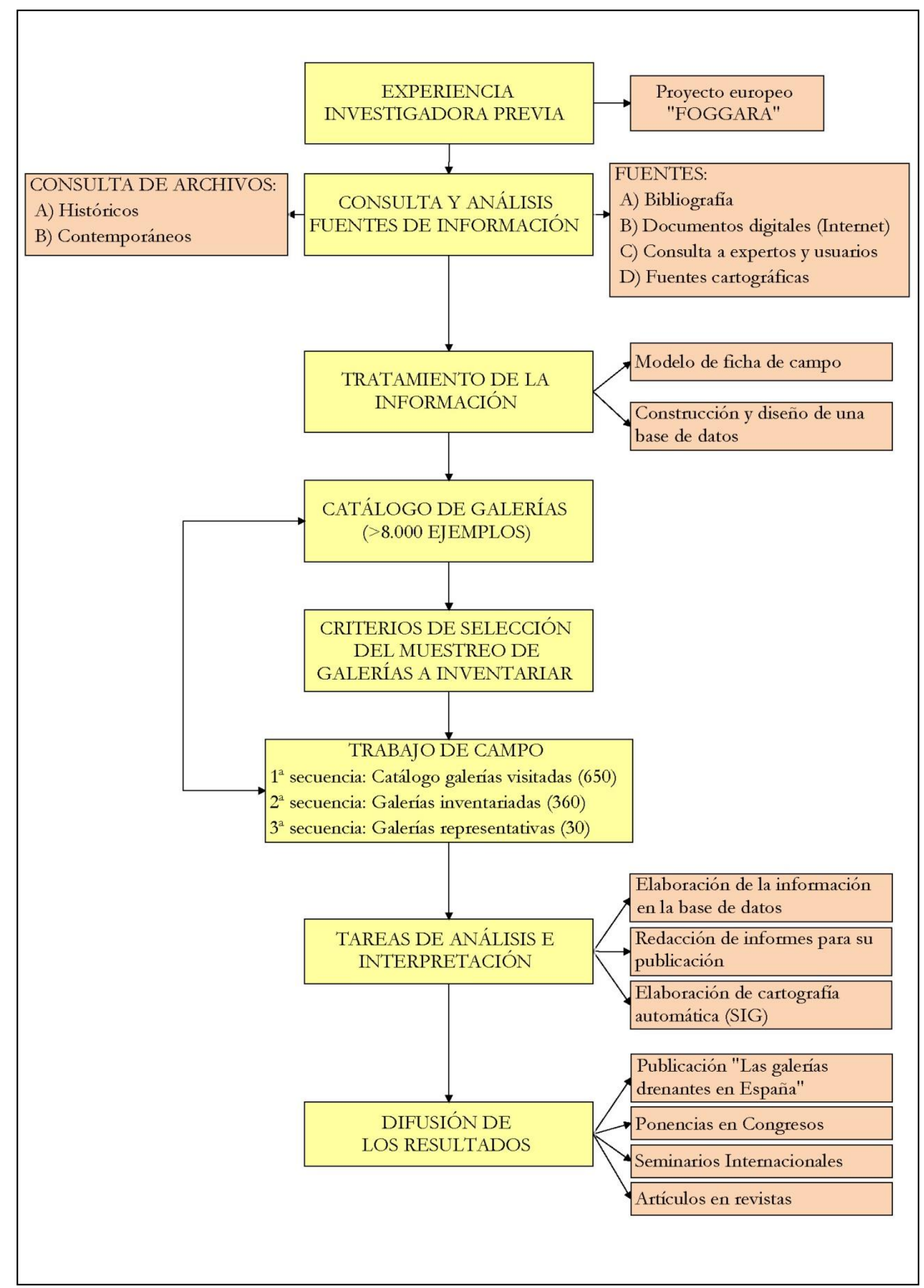

Fig. 1. Fases de la metodología para el estudio de las galerías drenantes españolas. 
Posteriormente se ha realizado un tratamiento de esa información, tras la recogida de datos in situ mediante un modelo de ficha de campo diseñado exprofeso; y el diseño y arquitectura de una base de datos espacial gestionada con un software SIG. Con las fuentes de información consultadas y con los datos georreferenciados incorporados a nuestra Infraestructura de Datos Espacial se ha confeccionado un inventario de galerías para el territorio español que se sitúa en los 8.000 ejemplos. Debido al elevado número de captaciones para ser operativos en nuestra investigación se ha considerado oportuno efectuar una selección de galerías., Para ello se ha establecido unos criterios de selección para discriminar las que van a formar parte del estudio. Estos han sido: a) Disponibilidad de información documental y cartográfica; b) La accesibilidad al interior de la captación; c) El buen estado de conservación; d) El equilibrio territorial entre los diferentes territorios españoles, de modo que existe representación en todas las Confederaciones Hidrográficas; e) La colaboración y consulta con los expertos; f) El trabajo de campo de proyectos anteriores.

Del conjunto de galerías identificadas 360 han sido estudiadas en profundidad; es decir son la base para realizar los distintos análisis y el ensayo de una clasificación tipológica de galerías. No obstante, también se ha efectuado un estudio pormenorizado de las galerías españolas más representativas (unas 30), por sus características históricas, paisajísticas, patrimoniales, constructivas o tipológicas. En ese análisis se pone una mayor incidencia en aspectos como la búsqueda de archivos y los materiales específicos para esas captaciones; un estudio del medio físico de mayor profundidad, con especial atención al contexto hidrogeológico; y un análisis del sistema de regadío y/o abastecimiento asociado, con su descripción y la cartografía del sistema.

Una vez finalizada la fase de trabajo de campo se realizan las labores de análisis e interpretación de los resultados. En esta etapa del estudio se trata la información que compone la base de datos con el objeto de extraer conclusiones y se confecciona la cartografía automática usando software SIG.

\section{Cuantificación y distribución territorial de las galerías españolas}

A nivel estatal existen únicamente dos fuentes de información que realizan una cuantificación de las galerías drenantes españolas. La primera es de principios del siglo XX y la constituye la Memoria de la Junta Consultiva Agronómica (JCA) de $1918^{1}$. En esta obra se realiza un análisis sobre las formas de proporcionar riego a las tierras y la distribución de los cultivos en la zona regable, apoyado en las fuentes estadísticas que remiten los ingenieros de cada una de las provincias. Entre los medios de captación de aguas se señalan los proporcionados por las galerías drenantes. En total se reseñan 527 galerías aunque este número debería ser mayor, debido a la inexactitud de las cifras en algunas provincias. Un ejemplo de ello lo vemos en Orense cuando se indica que existen galerías en todos los pueblos, pero sin especificar una cifra; o en Pontevedra donde el documento señala hay "muchas". En la provincia de Albacete se indica que hay "varias", pero sin más concreción. La superficie regable mediante galerías según esta fuente es de $36.664 \mathrm{Ha}$, lo que representa

\footnotetext{
1 Junta Consultiva Agronómica (1918): Medios que se utilizan para suministrar el riego a las tierras y distribución de los cultivos en la zona regable. Resumen hecho por la Junta Consultiva Agronómica de las Memorias de 1916, remitidas por los Ingenieros del Servicio Agronómico Provincial. Imprenta de los Hijos de M. G. Hernández, Madrid, 2 vol.
} 
el 2'68\% del total. Esta fuente posee un indudable valor histórico, aunque hay que tener en cuenta esas particularidades al interpretar sus datos.

La segunda fuente existente sobre galerías drenantes, que abarca la totalidad de España, la constituye la Base de Datos Aguas XXI, generada por el Instituto Geológico y Minero de España (IGME) en el año 2000. En total cataloga 2.133 minados, con las coordenadas georreferenciadas de cada una de las captaciones y con información diversa como el caudal, el uso al que se destinan las aguas, su composición química, su litología, etc. La cifra de galerías recogidas en esta base es sensiblemente inferior a otras fuentes de información disponibles, pero que lamentablemente no están completas para el conjunto del territorio nacional.

Tabla 1. Número de galerías drenantes en España según las fuentes de información que comprenden la integridad del territorio.

\begin{tabular}{ccc}
\hline Comunidad & \multicolumn{2}{c}{ Número de galerías } \\
\cline { 2 - 3 } Autónoma & JCA (1918) & IGME (2000) \\
\hline Andalucía & 267 & 1.045 \\
Aragón & 2 & 35 \\
Asturias & - & 45 \\
Baleares & - & 97 \\
Canarias & 77 & 468 \\
Cantabria & - & 1 \\
Castilla-La Mancha & $4^{(1)}$ & 76 \\
Castilla-León & - & 6 \\
Cataluña & 37 & 165 \\
C. Valenciana & 28 & 53 \\
Extremadura & - & 2 \\
Galicia & Muchas ${ }^{(2)}$ & 13 \\
La Rioja & 2 & 9 \\
Madrid & 3 & 20 \\
Murcia & 34 & 86 \\
Navarra & - & 0 \\
País Vasco & - & 12 \\
\hline TotaL & $\mathbf{5 2 7}$ & $\mathbf{2 . 1 3 3}$ \\
\hline
\end{tabular}

(1) En la provincia de Albacete el Ingeniero indica que hay "varias", pero sin especificar.

(2) El Ingeniero señala que en la provincia de Orense hay en todos los municipios, y para la de Pontevedra se indica que hay "muchas".

Además de las fuentes de información citadas existen otros organismos e instituciones que aportan listados con galerías georreferenciadas, como se observa en la tabla 2. Por un lado está la empresa ADARO, dependiente del IGME, que en algunas provincias como Almería realizó un inventario de los puntos de agua, incluyendo las galerías drenantes. Por otra parte las distintas Confederaciones Hidrográficas también poseen listados propios, aunque no todas ellas, por lo que sólo podemos tener esos datos para ciertas zonas del territorio. Así las Confederaciones Hidrográficas del Duero, Guadiana y del Sur no disponen de esos datos. En los últimos años parte de las tareas asumidas por las Confederaciones Hidrográficas han pasado a depender, en algunas autonomías, de Agencias del Agua propias, como ocurre en Cataluña, Baleares, Galicia o Canarias. Eso nos ha permitido 
recopilar un buen número de ejemplos de galerías en esos espacios, ya que esos organismos han creado su propia base de datos. Otra fuente de información que posibilita conocer un mayor número de captaciones georreferenciadas es el trabajo de campo de los principales grupos de investigación españoles y las publicaciones por ellos realizadas. La mayor parte proceden del grupo de Investigación ESTEPA, del Departamento de Geografía de la Universidad de Valencia (Hermosilla, 2006, 2008, 2011). En ese apartado también se han contabilizado las indicadas en las publicaciones sobre la isla de Mallorca del equipo de Miquel Barceló (1986); las de los profesores Gómez Espín y Gil Meseguer, de la Universidad de Murcia (Gil Meseguer y Gómez Espín, 1993, 2006; Gil Meseguer, 2007a, 2007b; Gil Meseguer et al., 2011); las obtenidas en Galicia por el Clube Espeleolóxico Maúxo de Vigo (Hermosilla, 2008); y las identificadas por el grupo de Irene de Bustamante para Madrid y la zona central de la península (López-Camacho et al., 1986; De Bustamante et al., 2003; López-Camacho et al., 2005).

Tabla 2. Número de galerías georreferenciadas por Comunidad Autónoma en los diferentes Organismos e Instituciones.

\begin{tabular}{|c|c|c|c|c|c|}
\hline C. Autónoma & $\begin{array}{l}\text { IGME } \\
(1)\end{array}$ & $\begin{array}{c}\text { Confederaciones } \\
\text { Hidrográficas }\end{array}$ & $\begin{array}{c}\text { Agencias del } \\
\text { Agua (2) }\end{array}$ & $\begin{array}{c}\text { Trabajo de } \\
\text { campo }\end{array}$ & Total \\
\hline Cataluña & 165 & 92 & 876 & 10 & 1.143 \\
\hline C. Valenciana & 53 & 25 & 98 & 539 & 715 \\
\hline Murcia & 86 & 86 & 24 & 148 & 344 \\
\hline Andalucía & 2.698 & 149 & - & 165 & 3.012 \\
\hline Galicia & 13 & 154 & - & 60 & 227 \\
\hline Asturias & 45 & 22 & - & - & 67 \\
\hline Cantabria & 1 & 3 & - & - & 4 \\
\hline País Vasco & 12 & 24 & - & - & 36 \\
\hline Navarra & - & 7 & - & - & 7 \\
\hline La Rioja & 9 & 32 & - & - & 41 \\
\hline Aragón & 35 & 43 & - & 16 & 94 \\
\hline Castilla-León & 6 & 23 & - & 2 & 31 \\
\hline Madrid & 20 & 65 & - & 50 & 135 \\
\hline Castilla-La Mancha & 76 & 85 & - & 149 & 310 \\
\hline Extremadura & 2 & - & - & 1 & 3 \\
\hline Baleares & 97 & - & 248 & 50 & 395 \\
\hline Canarias & 468 & - & 1.085 & 19 & 1.572 \\
\hline TOTAL & 3.786 & 810 & 2.331 & 1.209 & 8.136 \\
\hline
\end{tabular}

(1) En Almería también disponemos de los datos de la empresa ADARO, dependiente del IGME.

(2) Cataluña: Agencia Catalana de l'Aigua; Galicia: Augas de Galicia; Baleares: Agencia Balear del Agua; Comunidad Valenciana: Departamento del Ciclo Hídrico, Diputación Provincial de Alicante. Canarias: Consejos Insulares Insulares de Aguas.

A pesar de la disponibilidad de esta información estadística, con coordenadas georreferenciadas para cada minado, el análisis no ha estado exento de dificultades, generadas por la complejidad de la obtención de datos y los criterios utilizados para su clasificación por parte de las fuentes consultadas. La información generada por cada organismo o institución es bastante desigual y existe una importante disparidad en las cifras, para un mismo territorio. Las observaciones llevadas a cabo durante el trabajo de campo nos invitan a plantear que, en realidad, el número de galerías puede ser superior para el conjunto de España. Además en Cataluña, la Agencia Catalana del Agua, aunque posee un listado con 876 galerías con coordenadas UTM, advierte que existen 1.218 minados más en su territorio, aunque todavía no los había incorporado en su base de datos al realizar el estudio. 


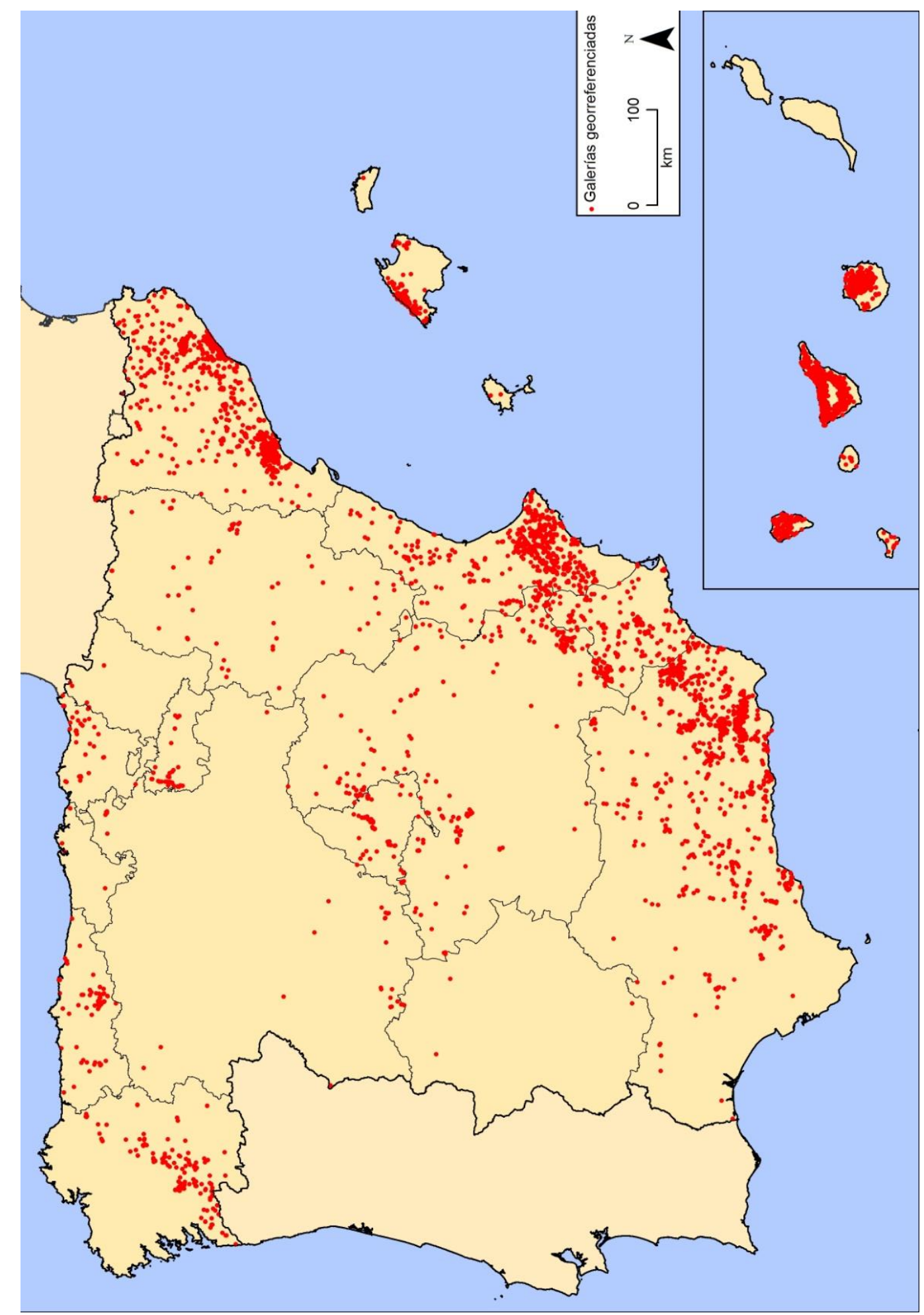

Fig. 2. Galerías drenantes georreferenciadas en España . 
Las galerías españolas se concentran principalmente en las provincias litorales de la franja mediterránea. Dentro de ellas el sector Sureste (provincias de Almería, Murcia y Alicante) presenta numerosos ejemplos, siendo la provincia española con más minados la de Almería con alrededor de 2.500 captaciones. En Cataluña se localizan principalmente en las provincias de Tarragona, con 592 galerías y en Barcelona, que posee 332 ejemplos. En el norte la mayor concentración se sitúa en Galicia, con 227 minados, aunque si se realiza un estudio en profundidad ese número se puede ver incrementado notablemente. Pese a ser una de las zonas más húmedas de la península, con lugares donde se superan los $2.000 \mathrm{~mm}$, las galerías gallegas se construyeron, en su mayor parte a finales del siglo XIX y principios del XX, para el abastecimiento de las múltiples entidades de población, aunque en algunos casos también se utilizan para el regadío, para superar el breve estiaje del periodo estival. En el interior peninsular destacan los "viajes de agua" de Madrid [22], además de las galerías de Aranjuez, Alcalá de Henares y Ocaña. La provincia de Albacete dispone a su vez de más de un centenar de captaciones.

Mención aparte merecen los dos archipiélagos, ya que en ambos se concentran un número considerable de captaciones. En Las Baleares existen unos 400 minados, situados en su mayor parte en la isla de Mallorca. En las Canarias se alcanzan casi las 1.600 captaciones. Estas galerías poseen diferencias considerables con el resto de las españolas, ya que un porcentaje muy elevado de las mismas comenzaron a construirse en los años '20 del siglo XX, aunque el mayor auge constructivo se produjo entre 1940 y 1960, para atender a las demandas agrícolas. Se caracterizan por ser minas sin lumbreras, que alcanzan longitudes considerables, en algún caso de hasta 5 o 6 kilómetros, construidas con técnicas mineras avanzadas, con sistemas de aire comprimido, ventilación, locomotoras y vagonetas para llegar hasta el frente y extraer el escombro, y explosivos para facilitar la remoción de los materiales excavados. Se localizan en las islas de Tenerife (1.047), Gran Canaria (339) y La Palma (167), y en el resto sólo tienen un carácter testimonial, debido a su escasa presencia.

\section{Tipología de galerías drenantes en España. Ensayo de clasificación}

Las galerías drenantes derivan el agua al exterior por medio de un túnel horizontal, aunque en función de la solución técnica empleada para el acopio de caudal, la tecnología utilizada en su perforación, el tipo de acuífero que captan y el espacio geográfico donde se localizan, se producen adaptaciones específicas, lo que da lugar a una amplia variedad tipológica. El qanat, que es el sistema original de captación de aguas subterráneas de modo horizontal, no ha permanecido intacto en su concepción tecnológica y arquitectónica, debido a que existe un mestizaje en las técnicas constructivas, para adaptarse a las necesidades concretas de cada área, según su litología, climatología, contexto hidrogeológico, etc. Eso posibilita que se pueda realizar un ensayo de clasificación.

No obstante la clasificación tipológica de las galerías es un tema abierto, ya que conforme se analiza un mayor número de casos, las tipologías y subtipologías pueden modificarse o aumentar. Las soluciones técnicas y funcionales pueden ser muy variadas, por lo que es probable que puedan aparecer minados con características peculiares que puedan suponer una nueva subtipología. El ensayar una clasificación de galerías posee una gran complejidad al existir varias dificultades: pueden coexistir principios de captación de varias tipologías y además pueden combinarse soluciones tecnológicas y arquitectónicas en el mismo minado; muy pocas veces existe documentación sobre el diseño y la construcción, lo que dificulta su inclusión en una u otra categoría; el emplazamiento en ambientes geográficos heterogéneos 
y la existencia de galerías en un contexto ambiental distinto al habitual para ese tipo de captaciones; y las alteraciones que ha sufrido la galería original debido a ampliaciones o tareas de mantenimiento, ya que provoca variaciones morfológicas que hacen variar su fisonomía (esto suele afectar especialmente a los pozos madres, ya que en ocasiones son cegados y resulta difícil conocer su estructura original).

La propuesta tipológica que realizamos se basa en tres criterios, complementarios entre sí, lo que posibilita la realización de varias clasificaciones. Esto nos permite elaborar un cuadro de síntesis en el que se integran los tres criterios, lo que supone la realización de un ensayo de tipificación. Los criterios son:

a) El origen de las aguas captadas, según el tipo de acuífero al que pertenecen, por lo que las aguas se agrupan en grandes categorías:

- Aguas subterráneas: son las que proceden de de acuíferos formados por fisuración o estratificación, además de los detríticos terciarios y cuaternarios que no estén en un ambiente de cursos y terrazas fluviales.

- Aguas subálveas y/o detríticas aluviales cuaternarias.

- Mixtas: puede ser por la combinación de aguas subterráneas y superficiales, o por la de aguas subálveas y/o detríticas aluviales cuaternarias y superficiales. Estos casos son excepcionales por lo que el número de galerías es muy reducido.

b) Las características constructivas y funcionales de las galerías, ya que la morfología de la edificación determina en ocasiones su tipología.

c) El ambiente geográfico donde se localizan las captaciones según sus características geomorfológicas: pueden ser de montaña (ladera, base de ladera y plataformas detríticas, calcáreas o tabulares), espacios intermedios (piedemontes, glacis y conos de deyección) y cursos y terrazas fluviales (lechos y terrazas fluviales, vaguadas y barrancos). Para determinar la ubicación en uno u otro ambiente nos apoyamos además en la pendiente existente, según la clasificación de Young y Young (1974), en la que la pendiente es inferior a $2^{\circ}$ o $3^{\circ}$ en llanuras y cursos y terrazas fluviales; en los ambientes de transición oscila entre $\operatorname{los} 2^{\circ}-3^{\circ}$ y los $10^{\circ}-12^{\circ}$; y en los de montaña la pendiente supera los $10^{\circ}-12^{\circ}$. No todas las galerías están ubicadas en el contexto geográfico que se les presupone en relación a sus técnicas constructivas, por lo que en algunas de ellas están descontextualizadas y fuera del ámbito geográfico donde suelen encontrarse habitualmente.

Las características constructivas y funcionales permiten establecer las tipologías y subtipologías, ya que cada una de ellas se define por modo de excavación y por la solución técnica utilizada para la captación del agua. En una misma galería pueden darse técnicas de construcción correspondientes a diferentes tipologías. Las principales tipologías y subtipologías de galerías presentes en España son las siguientes:

- Mina: su excavación se realiza por la profundización de una surgencia o manantial. Las aguas captadas tienen un origen subterráneo. No disponen de pozo madre ni de lumbreras verticales intermedias para la extracción de escombros. Suelen tener una longitud inferior a los 100 metros, salvo en las minas canarias, donde pueden alcanzar longitudes kilométricas. Ej. Arca del Agua (Guadalupe, Cáceres). 
- Mina con lumbrera: poseen las mismas características que las minas, pero con la particularidad de que en su trazado cuenta con una o dos lumbreras verticales, edificadas una vez la galería es profundizada y la distancia con la bocamina es mayor. Su principal localización suele producirse en ambientes de montaña. Ej. Mina de O Ulleiriño (Baiona, Pontevedra).

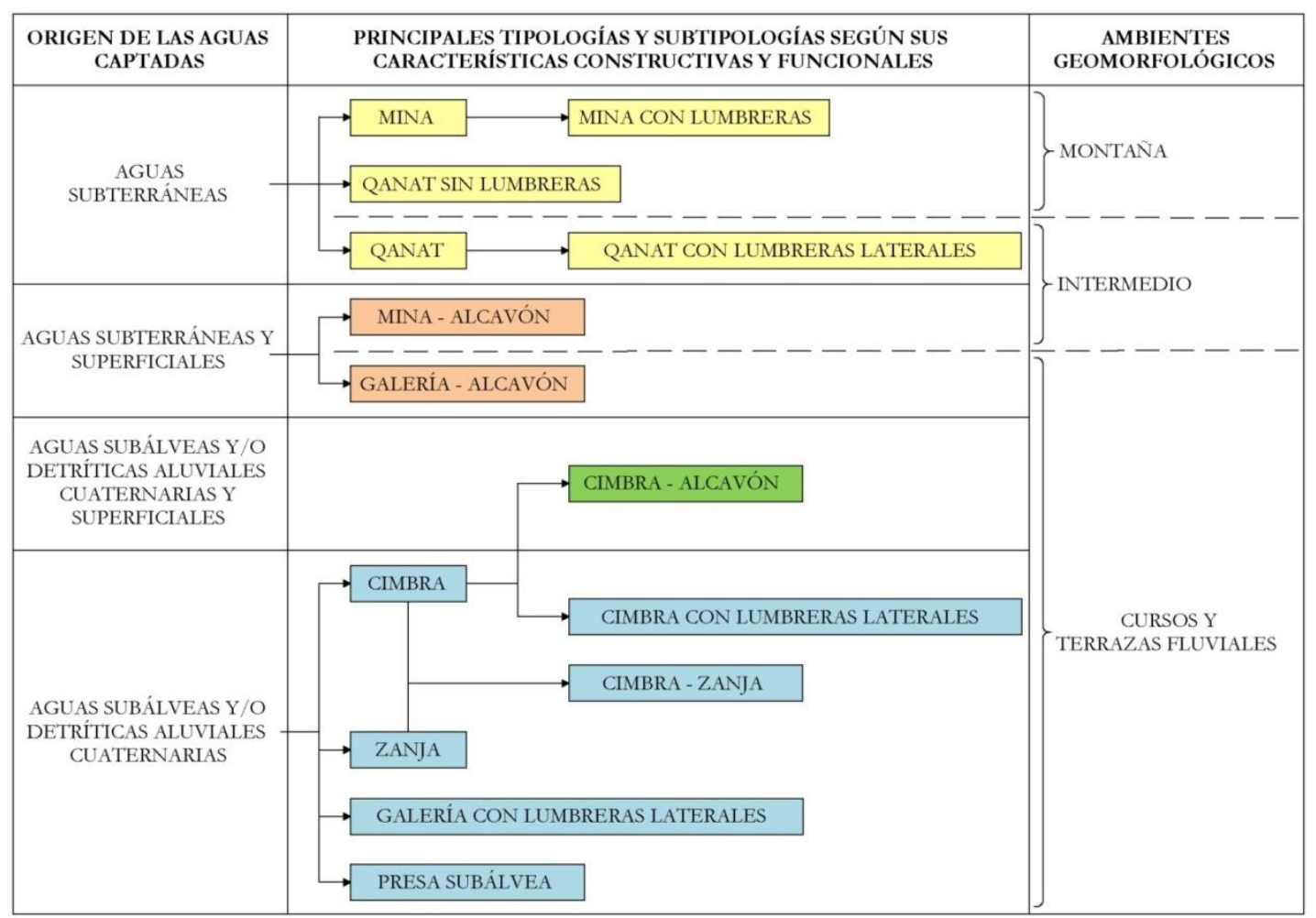

Figura 3. Ensayo de clasificación tipológica de las galerías drenantes españolas.

- Qanat sin lumbreras: el origen de la captación lo constituye el pozo madre, que se excava desde la superficie hasta alcanzar el nivel freático. Una vez construido, la galería se perfora desde la bocamina hasta el pozo madre. No dispone de lumbreras intermedias en su trazado. Ej. Mina Segunda de la Umbría (Ontur, Albacete).

- Qanat: es el sistema original en la captación de aguas subterráneas. La perforación comienza con la construcción del pozo madre, hasta llegar a la zona saturada del acuífero. Se caracterizan por disponer de varias lumbreras verticales o respiraderos en su trazado. Su ubicación más característica se encuentra en espacios intermedios o de transición como son los piedemontes, los glacis o los conos de deyección. Ej. Mina Pública d'Ajgües de Terrassa.

- Qanat con lumbreras laterales: es una subtipología que posee las mismas características que los qanats, pero además dispone de varias lumbreras laterales u horizontales cerca de la bocamina, cuya función es la de ser el inicio de una acequia de riego, al tiempo que facilita el acceso a la captación para tareas de construcción, limpieza y mantenimiento. Ej. El Molinillo (Lúcar, Almería). 
- Mina-alcavón: es un tipo de captación singular, ya que es una mina que se abastece con aguas subterráneas y superficiales. En la cabeza del minado existe una surgencia y posteriormente dispone de varias lumbreras. La galería se utiliza también como una galería filtrante, ya que recoge por medio de los hastiales y la bóveda, las filtraciones procedentes de la escorrentía subsuperficial, al tiempo que transporta el agua derivada del manantial situado en cabeza. Ej. Raudal de la Magdalena (Jaén).

- Galería-alcavón: aprovecha las aguas subterráneas y superficiales. Dispone de varias lumbreras laterales u horizontales y ninguna vertical. Además de las aguas captadas en la cabeza del minado existe un azud que posibilita la entrada de aguas desde el cauce fluvial por una de las lumbreras laterales, lo que la convierte en un caso excepcional de galería.Ej. Fuente de los Molinos del Río Aguas (Sorbas, Almería).

- Cimbra: suelen localizarse en un ambiente de cursos y terrazas fluviales y se aprovechan de las aguas subálveas y/o detríticas aluviales cuaternarias. No disponen de un pozo madre y cuentan con varias lumbreras verticales en su trazado. Se abren desde la bocamina hasta la cabeza mediante una excavación subterránea. Son características del sureste pensinsular, aunque también pueden estar presentes en otros espacios. Ej. Galería de las Angosturas (Jete-Almuñecar, Granada).

- Cimbra-alcavón: es una variedad de cimbra. Se sitúa en un ambiente de cursos y terrazas fluviales y obtiene su caudal de las aguas subálveas y/o detríticas cuaternarias, aunque en momentos de avenida pueden obtener un suplemento de aguas superficiales que se filtran por los hastiales y la bóveda de la captación, en su trazado por el subsuelo de la rambla. El origen principal del agua consiste en un minado situado en el interior de una excavación realizada a cielo abierto en la terraza fluvial en la cabeza del sistema. No dispone de lumbreras. Ej. La Fonnueva (Bulbuente, Zaragoza).

- Cimbra con lumbreras laterales: la particularidad de esta captación estriba en que tiene varias lumbreras laterales, que poseen la doble función de ser el inicio de una acequia de riego, antes de llegar a la bocamina, y la de ser un acceso a la captación para facilitar las tareas de limpieza y mantenimiento. Este subtipo de cimbra no dispone de pozo madre y cuenta con varias lumbreras verticales. Ej. Fuente del Abastecimiento Público (Santa Fe de Mondújar, Almería).

- Zanja: suelen ubicarse en cursos y terrazas fluviales. En su construcción no se utiliza una técnica minera, ya que se abre una zanja a cielo abierto en los materiales aluviales y posteriormente se cubre con lajas de piedra y se rellena con lo materiales removidos en su excavación. Es difícil encontrarlas en estado puro, ya que suele combinarse con otras técnicas constructivas. No tienen pozo madre ni lumbreras verticales en su recorrido. Ej. Fuente de la Montalvana (Torralba del Pinar, Castellón).

- Cimbra-zanja: esta tipología combina las técnicas constructivas de perforación subterránea, propias de las cimbras, con la excavación de una zanja a cielo abierto. Se ubican en un ambiente de cursos y terrazas fluviales. En su trazado cuenta con varias lumbreras verticales o pozos de aireación. Ej. Fuente Madre (Castejón de Monegros, Huesca).

- Galería con lumbreras laterales: se emplazan en ambientes de terrazas fluviales y utilizan técnicas propias de la minería en su excavación. Debido al espesor de los sedimentos de la terraza es más fácil acceder a la captación con una excavación horizontal, 
que perforando lumbreras verticales, mucho más profundas desde la terraza fluvial. Las lumbreras laterales se utilizan como el comienzo de un canal de regadío, anterior a la propia bocamina, y como un punto de acceso a la captación en el momento de su construcción o en el posterior mantenimiento. Ej. Salinas de la Ramona (Calasparra, Murcia).

- Presa subálvea: este tipo de captaciones se originan con una excavación en zanja, a cielo abierto de forma perpendicular a un lecho fluvial. Deben confluir unas condiciones hidrogeológicas adecuadas, caracterizadas por un importante paquete de arenas, gravas y cantos que recubran el lecho, y por debajo un nivel impermeable de base en un lugar estrecho que encierre el río o la rambla (Gómez Espín, 2004). Se construye una presa subálvea, de varios metros de profundidad que forma una especie de embalse subálveo que ante la presa enterrada, lo que permite captar la infiltración del lecho fluvial y recuperar gran parte del flujo subsuperficial que circula por el subálveo (Gil Meseguer et al., 2011). Existen dos tipos de presas subálveas: las que se encuentran antepuestas y adosadas a una galería, que disponen de un solo muro. Ej. Caño Viejo y Contracaño (Puerto Lumbreras, Murcia); y aquellas en que la galería está inscrita en la presa y forma parte de la misma, compuestas por dos muros paralelos entre sí entre los que se inscribe la galería. Ej. Fuente del Oro (Lorca, Murcia).

\section{Conclusiones}

El estudio e inventario que se ha efectuado para el conjunto de España sobre las galerías drenantes, con el cual se buscaba analizar la relevancia de estos elementos de captación hidráulica ha constatado dos hipótesis: el elevado número de captaciones subterráneas de agua existentes, para el conjunto peninsular e insular, y su variedad tipológica. Aunque el funcionamiento básico de estos minados es similar en todos ellos, ya que se encargan de la de extracción del agua del subsuelo al exterior por la fuerza de la gravedad, existen variaciones entre ellas, en función del tipo del agua captada, de sus técnicas constructivas y de funcionamiento, de los materiales que utilizan y de los ambientes geomorfológicos donde están excavadas.

Las galerías han sido construidas, bien con técnicas de excavación mineras, o mediante la excavación de una zanja y su posterior recubrimiento, cuando el nivel freático se halla a escasa profundidad, sobre todo en aquellas localizadas en el subálveo de los cursos y terrazas fluviales. En ocasiones se combinan en una misma captación ambas técnicas. La carencia de documentación escrita sobre el diseño original de las galerías dificulta su conocimiento por lo que el ensayo de una clasificación tipológica es una tarea compleja, en la que se continúa investigando. Existe una evolución técnica y un mestizaje tecnológico al existir una fusión de las técnicas constructivas, incluso en una misma galería, lo que se refleja en la tipología.

Aunque la franja mediterránea es la más prolija en cuanto al número de galerías en la península, existen captaciones en la práctica totalidad de regiones. También existe un número elevado en los dos archipiélagos, sobre todo en las islas de Tenerife y Gran Canaria. De los bienes que configuran el patrimonio cultural español los relacionados con patrimonio hidráulico, han sido y siguen siendo elementos mínimamente valorados y poco estudiados.Y dentro del patrimonio hidráulico uno de los elementos más singulares por su antigüedad y su concepción técnica son las galerías drenantes, pese a que aún sigan siendo un patrimonio desconocido, invisible, son decisivas en la configuración de numerosos paisajes asociados a los regadíos tradicionales y en el abastecimiento a diversos núcleos 
urbanos. Poseen un evidente valor patrimonial y en las últimas décadas varios grupos de investigación han analizado este tipo de captaciones, lo que puede contribuir a su mayor conocimiento y difusión. Su identificación, estudio y posterior puesta en valor pueden ser un medio efectivo para su conservación como bienes patrimoniales, así como una estrategia para el desarrollo socioeconómico de un territorio.

\section{Referencias}

Barceló, M. (dir.) (1986): Les aigües cercades (Els qanat(s) de l'illa de Mallorca). Institut d'Estudis Baleàrics, Palma de Mallorca.

Castro, M.; Martín-Vide, J.; Alonso, S. (2005): El clima de España: pasado, presente y escenarios de clima para el siglo XXI. In: Moreno, J. M. (Ed.): Evaluación Preliminar de los Impactos en España por Efecto del Cambio Climático. Ministerio de Medio Ambiente, Madrid, pp. $1-64$.

De Bustamante, I.; Sanz, J. Máa; Iglesias, J.A.; López-Camacho, B. (2003): Some examples of Spanish qanats. En InternationalesFrontinus-Symposium "Wasserversorgungaus Qanaten-Qanateals Vorbilderim Tunnelbau", 2-5 oktober 2003, pp. 173-186, Walferdange, Luxembourg.

El Faiz, M.; Ruf, T. (2010): An Introduction to the Khettara in Morocco: Two Contrasting Cases. In Schneier-Madanes, G.; Courel, M. F. (eds.): W ater and Sustainability in Arid Regions. Bridging the Gap Between Physical and Social Sciencies. Ed. Springer Science+Business Media B. V., pp. 151-163.

García, J.; Iranzo, E.; Hermosilla, J. (2008): Galerías drenantes: definición, concepto, tipologías e identificación a escala mundial. In Hermosilla, J. (dir.): Las galerías drenantes en España. Análisis y selección de qanat(s). Colección Gestión tradicional del agua, patrimonio cultural y sostenibilidad, No2, pp. 17-28. Ed. Ministerio de Medio Ambiente y Medio Rural y Marino.

Gil Meseguer, E.; Gómez Espín, J. M. (1993): Galerías con lumbreras en el sureste de España, Papeles de Geografía, 19, pp. 125 - 145.

Gil Meseguer, E.; Gómez Espín, J. M. (coord.) (2006): Modelos de sostenibilidad en el uso del agua en la Región de Murcia. Colección Usos del agua en el territorio, No3. Servicio de Publicaciones de la Universidad de Murcia, 159 pp.

Gil Meseguer, E. (coord.) (2007a): Sistemas locales de recursos propios de agua en la región de Murcia: Minados y Galerías. Colección Usos del Agua en el Territorio, No4, Universidad de Murcia, 190 pp.

Gil Meseguer, E. (coord.) (2007b): Sistemas locales de recursos propios de agua en la región de Murcia: Minados y Galerías. Colección Usos del Agua en el Territorio, No4, Universidad de Murcia, 190 pp.

Gil Meseguer, E.; Martínez Medina, R.; Gómez Espín, J.Ma (2011): Modelos de uso sostenible del agua: las galerías asociadas a presa subálvea. Scripta Nova, Revista Electrónica de Geografía y Ciencias Sociales, Universidad de Barcelona, Vol. XV, No374. 
Goblot, H. (1979): Les Qanats, une technique d'acquisition de l'eau. École des Hautes Études en Sciences Sociales, Ed Mouton, París.

Gómez Espín, J. Ma (2004): Aprovechamiento integral del agua en la Rambla de Nogalte (Puerto Lumbreras-Murcia). Colección Usos del agua en el territorio, No1. Servicio de Publicaciones de la Universidad de Murcia, 190 pp.

Hermosilla, J. (dir.) (2006): Las galerias drenantes del Sureste de la Peninsula Ibérica. Colección Gestión tradicional del agua, patrimonio cultural y sostenibilidad, No1. Ed. Ministerio de Medio Ambiente, Madrid, 226 pp.

Hermosilla, J. (dir.) (2008): Las galerías drenantes en España. Análisis y selección de qanat(s). Colección Gestión tradicional del agua, patrimonio cultural y sostenibilidad, No2. Ed. Ministerio de Medio Ambiente y Medio Rural y Marino, 269 pp.

Hermosilla, J. (dir.) (2012): Las galerías de agua en la cuenca bidrográfica del Júcar: un patrimonio bidráulico en el Mediterráneo español. Colección Patrimonio Hidráulico, No3, 229 pp. Ed. Confederación Hidrográfica del Júcar y Departament de Geografia, Universitat de Valencia.

Hermosilla, J.; Moussa, M. (dirs.) (2011): Las galerías de agua tunecinas. Las gobernaciones de Kebili, Tozeur, Gafsa y Gabès. Ed. Departament de Geografia, Universitat de València, 182 pp.

Hermosilla, J.; Moussa, M. (dirs.) (2012): Paisaje y galerías de agua en la región centro-oriental de Túnez. Las gobernaciones de Sousse, Monastir, Mahdia, Sfax y Kairouan. Ed. Departament de Geografia, Universitat de València, 252 pp.

Hermosilla, J.; Moussa, M. (dirs.) (2013): Las galerías de agua en la región noroccidental de Túnez: Patrimonio hidráulico mediterráneo. Ed. Departament de Geografia, Universitat de València, 308 pp.

Kobori, I. (1979): Qanawat Romani of Taibe Oasis. Bulletin of Department of Geography University of Tokyo, 11, pp. 1-32.

Lambton, A. K. S. (1989): The origin, diffusion and functioning of the Qanat. In Beaumont, P.; Bonine, M. E.; McLachlan, K. S.: Qanats, Kariz\&Khattara: Traditional Water Systems in the Middle East and North Africa. Menas Press (Middle East and North African Studies), University of London, pp. 5-12.

Lightfoot, D. R. (2000): The origin and difussion of qanats in Arabia: new evidence from the Northern and Southern Peninsula. The Geographical Journal, 166 (3), pp. 215-226. Ed. The Royal Geographical Society, University of London.

López-Camacho, B.; Bascones, M.; De Bustamante, I. (1986): El agua subterránea en Madrid. Boletín de Informaciones y Estudios, 46, Junio, pp. 73 - 127, Ministerio de Obras Públicas y Urbanismo, Madrid.

López-Camacho, B. (2001): Galerías de captación de agua en la Europa Mediterránea. Revista de Obras Públicas, No 3.414, pp. 121-126, Madrid.

López-Camacho, B.; De Bustamante, I.; Iglesias, J. A. (2005): El viaje de agua (qanat) de la Fuente Grande de Ocaña (Toledo): pervivencia de una reliquia hidráulica. Revista de Obras Públicas, No3.451, pp. 43-54, Madrid. 
Young, A.; Young, D. (1974): Slope Development. Macmillan Education, 35 pp. 